Anales de Historia del Arte

ISSN: 0214-6452

http://dx.doi.org/10.5209/anha.66052

\title{
Breve historia del Museo del Prado
}

Francisco Calvo Serraller ${ }^{1}$

\section{El origen de los museos públicos}

E1 19 de noviembre de 1819 se inauguró el Museo del Prado o, como entonces se le denominaba, el Museo Real de Pinturas, pues sus fondos procedían de las colecciones de los reyes de España. Fue uno de los primeros museos públicos que se crearon, siguiendo el modelo francés del Louvre, que abrió sus puertas el 11 de agosto de 1793, dos años después de que fuera aprobada su constitución por el entonces bisoño gobierno revolucionario de la República. De hecho, la creación de museos públicos fue una de las ideas más ardientemente promovidas por la Revolución francesa, ideas que luego fueron llevadas a la práctica por toda Europa gracias al Imperio napoleónico.

Evidentemente, la invención del museo data de mucho más antiguo, como lo delata el propio término, que es una palabra griega que significa «lugar de las musas», o, en una interpretación más libre, algo así como «lugar de inspiración». En realidad, la idea de crear un museo es históricamente tan remota como la pasión humana por coleccionar o atesorar objetos, que se remonta a la misma noche de los tiempos. En todo caso, las colecciones toman forma como museos en la cultura occidental a partir, como otras cosas, de la antigua Grecia, pero se convierten en lo que son hoy aproximadamente desde el siglo XVIII, cuando triunfan las ideas revolucionarias de la Ilustración, lo que explica que haya sido en nuestra época el gran momento de la proliferación infinita de este tipo de instituciones.

Así pues, la clave distintiva de nuestros museos, respecto a todos los precedentes de los siglos anteriores, consiste no solo en su carácter público, sino, consecuentemente, en su finalidad educativa. En efecto, el nuevo Estado consideraba la educación y la cultura instrumentos primordiales para combatir la desigualdad social heredada, por lo que trató de que se universalizasen empleando todos los medios a su alcance, cada vez más poderosos. En este sentido, aunque las obras de arte, por su naturaleza suntuaria, resultaban comparativamente más difíciles de democratizar, los poderes públicos también se empeñaron en su promoción social a través precisamente de los museos. Estos no tenían necesariamente que estar dedicados al arte, pero los que sí lo estaban enseguida cobraron una mayor importancia y prestigio, tanto por el altísimo valor económico de esta clase de objetos, como por su ejemplar significación histórica que, además, reflejaba idealmente la identidad nacional de una colectividad, algo fundamental para el nuevo modelo de Estado que se estaba imponiendo en la naciente época contemporánea.

Publicado previamente en Calvo Serraller, Francisco, Introducciones al museo del Prado (edición a cargo de Javier Portús y Alberto Pancorbo) Madrid, 2015, Fundación de amigos del Museo del Prado, pp. 32-59. 
Convertidos los museos públicos en los templos de la sociedad secularizada, debieron simultáneamente hacer compatibles el anhelo social de nacionalizar el patrimonio artístico de un país y el de refrendar la naturaleza universal, cosmopolita, del arte. De esta manera, al satisfacer la aspiración humanista de universalidad a través de la experiencia histórica concreta y particular de un pueblo y, asimismo, al lograr un cierto sentido de trascendencia, como le había sido propio hasta ese momento a la religión entonces declinante, a través de un conjunto de carismáticos objetos materiales, el museo adquirió una extraordinaria significación social. Por otra parte, hay que insistir en que los museos eran prácticamente el único instrumento del que disponía el Estado para una eficaz democratización del arte, que, inicialmente, solo constaba de ejemplares únicos y apreciados precisamente por ser únicos.

Volviendo ahora, no obstante, sobre la historia de la creación del Musée du Louvre, que se convirtió en el modelo del resto de los museos europeos, importa resaltar su original vocación «nacionalizadora» de un patrimonio artístico hasta entonces detentado casi en exclusiva por la aristocracia y la Iglesia, así como, en relación directa con esa voluntad de servicio público, su orientación didáctica y recreativa. En este sentido, pronto apuntó una polémica entre si los criterios rectores de la nueva institución deberían responder a un patrón «artístico» o a otro «histórico», siendo esta última la forma de denominar, en aquel momento, a lo que después, de una manera más pedante, se conocería como «científico». Huelga casi decir que lo que se ventilaba tras la primera opción era la de un museo dirigido por artistas, mientras que, tras la segunda, la de un museo dirigido por historiadores del arte o arqueólogos. En cualquier caso, fuera cual fuese la opción elegida, el nuevo museo público no solo se dedicó a acumular el máximo número de obras de arte, sino a presentarlas de una manera ordenada, aunque, inicialmente, la razón de este orden basculara entre el modelo barroco, más efectista y ornamental, y el modelo ilustrado, basado en un sistema de progresión histórica, sesgado mediante la articulación de las diferentes escuelas nacionales.

\section{Principales antecedentes españoles del Museo del Prado}

Todo esto, naturalmente, también repercutió en la fundación y el desarrollo histórico del Museo del Prado, que se inauguró oficialmente, como ya se dijo al principio, en 1819 , pero no sin que previamente dejaran de suceder una serie de acontecimientos preparatorios o antecedentes, que conviene ahora glosar de forma abreviada y que comienzan con la que se puede considerar la primera iniciativa para establecer un museo de pinturas en la capital de España, que data del primero de septiembre de 1800. En dicha fecha, Mariano Luis de Urquijo, secretario de Estado, da la orden de trasladar a la corte los cuadros de Murillo conservados en el Hospital de la Caridad de Sevilla y justifica su decisión indicando que en todas las cortes de las naciones cultas de Europa se forman escuelas y museos.

Si el antes reseñado es el más antiguo de los antecedentes, el más significativo, sin duda, fue el frustrado proyecto del no menos frustrado monarca José Bonaparte I, ese que justamente se conoce como Museo Josefino, cuyo decreto fundacional fue publicado el 21 de diciembre de 1809. Los cuatro artículos de los que constaba dicho decreto apenas sí aclaraban que el museo se ubicaría en Madrid, pero aún sin 
determinar exactamente la sede; que, además, se seleccionaría un conjunto con los mejores maestros españoles para enriquecer el Museo Napoleón, de París, «siendo -se decía- un monumento de la gloria de los artistas españoles»; y, en fin, que también se emplazarían cuadros en diferentes dependencias oficiales. Quizá lo más interesante de este primer decreto era su preámbulo, puesto que reflejaba tanto esa doctrina revolucionaria que inspiró la creación de los primeros museos públicos, como su puesta en práctica por el Imperio napoleónico. Comenzaba así:

Queriendo en beneficio de las bellas artes disponer de la multitud de cuadros, que separados de la vista de los conocedores, se hallan hasta aquí encerrados en los claustros; que estas muestras de las obras antiguas más perfectas sirvan como de primeros modelos y guías a los talentos; que brille el mérito de los célebres pintores españoles, poco conocidos de las naciones vecinas, procurándoles al propio tiempo la gloria inmortal que merecen tan justamente [...] hemos decretado [...].

Con esta iniciativa José Bonaparte no hacía sino efectivamente continuar la política imperial napoleónica, que había impulsado a Luis Napoleón Bonaparte, a la sazón rey de Holanda, a fundar el Koninklijk Museum, de Amsterdam, antecedente directo del Rijksmuseum, el 21 de abril de 1808, o al rey Jerónimo Bonaparte, de Westfalia, a hacer otro tanto en la ciudad de Kassel. En todo caso, de todas estas iniciativas de la familia Bonaparte, la única que acabó cuajando por completo fue la de la Pinacoteca de Brera, de Milán, que se inauguró el 15 de agosto de 1809, unos pocos meses antes, por tanto, de que apareciera el decreto fundacional del Museo Josefino, de Madrid. Museo que se pensó ubicar en el Palacio de Buenavista - construido en un solar situado entre la calle de Alcalá y el paseo de Recoletos-, aunque, en vista de las dificultades funcionales que este edificio planteaba para un adecuado uso museístico, a partir de septiembre de 1811 surgió también un anteproyecto de utilización de la aún no terminada Academia de Ciencias Naturales del paseo del Prado, precisamente la que posteriormente daría origen al actual Museo del Prado, pero que entonces estaba sirviendo como acuartelamiento de las tropas francesas en Madrid.

La suerte de la guerra de la Independencia acabó, como se sabe, con este proyecto, que, de todas formas, fue el antecedente más claro de lo que, diez años después, supondría la inauguración del Museo del Prado. También es cierto que hubo otros precedentes, más o menos difusos, como el que se ideó en 1800 durante el reinado de Carlos IV, pero ni este, que apenas se podría calificar como anteproyecto, ni el espigamiento de otros testimonios ilustrados, que no traspasaron el umbral de meras declaraciones desiderativas, pueden servirnos para otra cosa que simplemente para mostrar que la creación de un museo era algo que estaba madurando entre los políticos españoles de ese momento dominado por las Luces.

Por lo demás, hubo una diferencia significativa entre estos precedentes y la definitiva creación del Museo Real de Pinturas que promovió Fernando viI, y esta radicó en la naturaleza de sus fondos, pues, como ya se apuntó al principio, el museo inaugurado en 1819 se constituyó exclusivamente con los cuadros de la colección real, lo que determinó bastante la historia y la personalidad de la institución. Sea como sea, antes de dicha inauguración se consumió un tiempo no breve entre deliberaciones y planes, que conviene traer a colación muy someramente. 


\section{Las razones de Fernando VII para fundar el museo}

Debe señalarse que, tras finalizar la guerra, la Academia de Bellas Artes de San Fernando pretendía crear una galería de pinturas en Madrid con las obras almacenadas por las tropas francesas, para lo que solicitaba al rey un local espacioso donde situar tanto la Academia como esta galería, decidiendo su junta que este podía ser el Palacio de Buenavista, edificio que prefería la Academia por la proximidad a su sede de la calle de Alcalá. Pero la oposición al proyecto de algunos políticos y los problemas financieros de la Academia, que se encontró incapaz de costear los gastos de la necesaria remodelación del edificio, hicieron que, poco a poco, el museo que se estaba proponiendo fuese cada vez menos un museo de la Academia de Bellas Artes y cada vez más un museo del rey.

El primer dato curioso al respecto fue la prontísima manifestación del deseo de crear un museo de pinturas por parte del recién repuesto monarca, Fernando viI, que entró triunfalmente en Madrid el 13 de mayo de 1814 y, antes de que hubieran transcurrido un par de meses, el 4 de julio de ese mismo año, ya firmaba una real orden declarando su intención de ceder el requisado Palacio de Buenavista a la Academia de San Fernando para disponer en él una galería de pinturas y otros objetos de interés artístico, galería a la que, además, el propio monarca se comprometía a proveer con obras sobrantes de los reales sitios. No conocemos con precisión el motivo de esta súbita munificencia por parte de un rey que no destacó especialmente por su pasión por el arte contemporáneo, pero, por de pronto, es casi seguro que debió de sentirse influido por la iniciativa precedente del «usurpador» José Bonaparte, así como por haber podido constatar el interés que habían manifestado todos los extranjeros combatientes en suelo español durante la guerra de la Independencia por el patrimonio artístico español.

Junto a estas razones de peso, también se han manejado otras motivaciones, que, por comparación, hay que calificar de menudas, como, por ejemplo, la instigación de determinados personajes del círculo íntimo y hasta familiar del monarca. Entre estos destaca uno, bastante enigmático, Isidoro Montenegro y Morentes, que le había acompañado durante su exilio en Francia y que, tras la restauración, ocupó cargos cortesanos de confianza, como el de manejar los «fondos reservados» del rey, a partir de los cuales se dotó al recién creado museo. Rehecho, años más tarde, el tal Montenegro se atribuía el haber sido el promotor de la iniciativa sin que entonces nadie le discutiera el privilegio. También debió de desempeñar un no pequeño papel en la empresa doña Isabel de Braganza, la reina, de la que sabemos era una gran aficionada a las artes y a la que retrató póstumamente Bernardo López Piquer, representándola de cuerpo entero, apoyando una mano sobre los planos del Museo y señalando con la otra al edificio de Villanueva, cuya silueta se recorta al fondo del cuadro.

Rey inicialmente más deseado que ninguno, pero también muy pronto más odiado que lo que cabe imaginar, Fernando VII no se libró de las leyendas negativas más peregrinas, incluso en relación con los temas más políticamente irrelevantes o inocuos. En este sentido, y en lo que atañe a la fundación del Museo del Prado, corrió la especie, de la que se haría eco un ilustre viajero romántico, el británico Richard Ford, de que el rey había transferido al naciente Museo tan rica selección de sus mejores cuadros para así poder decorar el Palacio Real con el empapelado de las paredes, al dictado de la moda francesa. Fuera como fuese, no hace falta entrar a calibrar lo que pudiera haber de veraz en esta maliciosa interpretación, porque frente a ella, no solo 
se impone la rotundidad fáctica de la generosa iniciativa, sino la más elocuente de haber costeado Fernando vII de su propio bolsillo los muchos gastos de la remodelación del edificio y, sobre todo, los de su ulterior mantenimiento.

\section{Historia del Real Museo de Ciencias Naturales}

Conviene saber que la causa principal del lapso de tiempo que transcurrió entre la primera declaración documental en la que el rey manifestaba su deseo de crear un museo y la inauguración oficial de este, esos cinco años que separan 1814 de 1819, se consumieron principalmente en la búsqueda de cuál sería el emplazamiento ideal y, una vez decidido que debería ser el inacabado y destartalado Real Museo de Ciencias Naturales, en su remodelación y adecentamiento. Aunque parezca mentira, se tardó mucho menos en lo segundo que en lo primero, lo que nos hace suponer que esas dudas acerca de cuál había de ser el emplazamiento ideal debieron de estar acompañadas de graves dificultades de tesorería, muy lógicas en un país recientemente esquilmado por una cruenta guerra. En todo caso, el proyecto tomó un impulso definitivo en 1818, fecha en la que se decidió utilizar el edificio de Villanueva como sede del nuevo museo, quedando prácticamente ultimadas las obras en el verano de 1819, aunque se pospuso la inauguración hasta noviembre de ese mismo año por aguardar a la celebración de los nuevos esponsales de Fernando viI con su tercera mujer, doña María Josefa Amalia de Sajonia.

Sobre el edificio en cuestión, el tradicionalmente conocido como Real Museo de Ciencias Naturales, cuya cimentación comenzó en 1785 y cuyo virtual remate se producía en 1808, Antonio Rumeu de Armas publicó una interesante investigación, en la que demostraba que se trataba de una mucho más ambiciosa iniciativa, consistente en una Academia de Ciencias, que, además de albergar, como se creía, un gabinete de historia natural, dispondría de laboratorios de química, un gabinete de máquinas, una escuela de mineralogía y un observatorio astronómico. Desde luego, solo así se comprenden las enormes dimensiones del edificio y su privilegiado emplazamiento en el Prado de los Jerónimos, una de las zonas urbanísticamente más mimadas por el emprendedor Carlos III. Parece ser que el primer causante del equívoco al transformar tan vasto proyecto científico en un simple Museo de Ciencias Naturales fue el arquitecto encargado de la obra, Juan de Villanueva, pero el desmembramiento fáctico de su contenido tuvo que ver con la marcha de los acontecimientos, de manera que, aún continuándose las obras, ya en época de Manuel Godoy, había poco interés en dotarlo para el uso científico con el que originalmente había sido planeado. Por lo demás, el destrozo que en él ocasionaron las tropas francesas, que lo convirtieron en cuartel de caballería y que aprovecharon los ricos emplomados de su techumbre para la fabricación de balas, dejaron en un estado lamentable este bello e imponente edificio antes incluso de que pudiera cumplir con ninguna función.

\section{Características del edificio de Villanueva y sus posteriores remodelaciones}

Se puede comprender entonces que, estando en semejante ruina y ocupando un lugar tan bello y concurrido como el paseo del Prado, Fernando VII y sus consejeros se fijaran en él como esa tan buscada sede del nuevo museo de pinturas, ya que, además 
de adecuarse perfectamente para este cometido, se lograba restaurar una fábrica tan noble y tan visiblemente maltratada. La obra diseñada por Juan de Villanueva desde luego se lo merecía, con sus tres grandes cuerpos, unidos entre sí por dos alargadas galerías. Muerto Villanueva, intervino en su remodelación y adecentamiento el mejor discípulo de este, Antonio López Aguado, que fue quien lo dejó listo para ser inaugurado en 1819. De todas formas, desde esta primera apertura oficial del Museo, el edificio ha sufrido notables transformaciones, un poco al hilo de la progresiva importancia que iba adquiriendo la institución y el correspondiente incremento de sus colecciones. En este sentido, al principio se trató de subvenir las necesidades de espacio acometiendo la construcción de las partes proyectadas por Villanueva, pero que aún restaban por edificar; posteriormente, mediante la transformación de algunos cuerpos o la simple adición de salas nuevas.

Haciendo ahora, en todo caso, un somero repaso de las principales intervenciones llevadas a cabo en el edificio a través de su ya dilatada historia, hay que destacar, al menos, una media docena anteriores a 1980, fecha a partir de la cual comenzó a plantearse la necesidad de realizar una ampliación que solucionase de forma definitiva los problemas de espacio del Museo. Antes de comentarlas, conviene completar con más detalle ese proyecto original de Villanueva, que estaba estructurado en tres cuerpos y sendas galerías de enlace. Pues bien, el cuerpo central estaba realzado con un pórtico exterior monumental y se prolongaba hasta formar una edificación a modo de basílica. De esta manera, y según la autorizada interpretación de Fernando Chueca, el conjunto completo respondería a una secuencia, que, de norte a sur, y en relación con los tres cuerpos monumentales reseñados, podría describirse como vestíbulo, basílica y palacio, correspondiéndose el primero con la hoy denominada Puerta de Goya y el último con la también hoy conocida como Puerta de Murillo, frontera con el Jardín Botánico.

Pero, encarando ya esa relación sustancial de intervenciones acometidas en el edificio de Villanueva, debemos comenzar por la que supuso la construcción de la basílica y el ábside del cuerpo central en 1853, según el diseño de Narciso Pascual y Colomer, a la que sucedieron las siguientes: entre 1882 y 1885, la transformación de la fachada norte, que emprendió Francisco Jareño, el cual vació el terraplén allí existente y, en su lugar, adosó una espectacular escalera monumental, además de modificar la llamada Sala de la Reina Isabel y abrir ventanas en la parte baja cegada, ambas producto de la anterior intervención de Colomer en el cuerpo central; en 1923 se inauguraron las salas ampliadas en la parte posterior del edificio, obra esta de Fernando Arbós; en 1927, Pedro Muguruza hizo una bellísima remodelación en hormigón de la galería central, siendo este mismo arquitecto el que, años más tarde, en 1943, modificaría la escalera monumental de la fachada norte con vistas a lograr una mejor iluminación en la enterrada cripta de la parte baja; en 1956 y 1967, respectivamente, se realizaron sendas ampliaciones de las salas, siendo los autores de la primera Fernando Chueca y Manuel Lorente y de la segunda José María Muguruza.

Un recuerdo exacto de todas las intervenciones, incluidas las de naturaleza tecnológica, como las obras de climatización artificial del Museo, resultaría innecesariamente prolijo, de manera que nos vamos a conformar con las antes citadas, que son las que verdaderamente han configurado el aspecto actual del edificio ideado por Juan de Villanueva. Como quiera, no obstante, que, tras la postrera ampliación de salas de 1967, persistían las estrecheces de espacio, pues no solo crecía la colección, sino que se modificaba el criterio de exposición tradicional heredado del siglo XIX, 
se comenzó a pensar en buscar un desahogo en otro edificio colindante, teniendo en cuenta que nuevas intervenciones en el de Villanueva ya solo eran concebibles a partir de una gravísima alteración de su estructura original, lo que supondría un atentado a una pieza singularísima del patrimonio arquitectónico español. Desde esta perspectiva se explica la decisión de incorporar, en 1971, el Casón del Buen Retiro al Museo del Prado, aprovechando una redistribución de las colecciones nacionales. De esta manera, a partir de esta fecha, el Casón albergó las obras de los siglos XIX y xx que pertenecían al Prado.

Así y con todo, nuevos problemas asediaron al Museo, como los derivados de la afluencia masiva de visitantes y los servicios públicos que comportaba. A partir aproximadamente de 1970, cuando, al socaire de la prosperidad económica del mundo occidental, se produjo una formidable industria turística de masas, los mejores museos del mundo se convirtieron en lugares de visita obligada, desbordándose por completo su capacidad tradicional de recepción de público. Con ello también varió sustancialmente el tipo de visita, que se hizo más exigente, pues se había elevado asimismo el nivel de información. En este sentido, los grupos organizados y las estancias prolongadas en el Museo, entre otras vicisitudes, plantearon un variopinto catálogo de nuevos usos museísticos, como salas de recepción, de conferencias, de proyección, biblioteca, etc., pero también lugares de descanso y esparcimiento, como cafeterías y restaurantes, por no hablar ya de los guardarropas, equipamientos sanitarios y la adecuación espacial y técnica para los visitantes con minusvalías físicas. Fue entonces, además, cuando se comprendió la simultánea necesidad de reduplicar los efectivos humanos con los que contaban los museos, ya que, en función de lo antes expuesto, no solo era necesario multiplicar el personal de celadores, sino incorporar toda una serie de nuevos oficios más o menos sofisticados, así como, por supuesto, ampliar considerablemente el número de conservadores y restauradores, la única forma para que, como se puso de moda decir entonces, el Museo no pareciera «muerto».

Todo esto supuso una verdadera revolución en la vida de los museos, que iniciaron cambios que distan aún mucho de estar concluidos. El Museo del Prado sintió en su propia estructura del histórico edificio de Villanueva los primeros síntomas del desbarajuste con motivo de las obras de climatización artificial, que asediaron la vida de la institución en la segunda mitad de la década de 1970, a la vez que replantearon todo el resto de las nuevas necesidades, cuya puntual satisfacción implicaba la correspondiente pérdida de espacio expositivo. Tal es la razón de que, a partir de 1980, arreciaran las peticiones de ampliación exterior del Museo, peticiones que, pese a las distintas propuestas y actuaciones llevadas a cabo por la Administración y el Museo, siguieron escuchándose en las siguientes décadas, resonando con fuerza incluso una vez traspasado el umbral del siglo Xx.

Dejando a un lado la propuesta, presentada en 1976 y un tanto descabellada por otra parte, de trasladar las obras de Francisco de Goya al pabellón de semilleros del Jardín Botánico, ampliándolo y adaptándolo a su nuevo uso, y otras de parecida índole, como la de utilizar para ampliar el Museo la sede del Ministerio de Agricultura, una de las primeras propuestas de ampliación surgió en 1981, cuando desde la Dirección General de Patrimonio Artístico se planteó que el edificio del Palacio de Villahermosa, pudiera utilizarse para ampliar el Museo del Prado, y ya en ese mismo año el ministro de Cultura, Ínigo Cavero, declaraba que el Estado estaba ultimando la compra de dicho palacio para la ampliación del Museo del Prado. Pero no será hasta 1984 cuando se confirme 
la adquisición del Palacio de Villahermosa por el Ministerio de Cultura, así como la anexión al Prado del Salón de Reinos del palacio del Buen Retiro, sede del Museo del Ejército, para la ampliación del Museo. En cualquier caso, volviendo al Palacio de Villahermosa, este edificio fue primero sede de exposiciones temporales organizadas por el Museo del Prado -la primera de las cuales, Pintura napolitana. De Caravaggio a Giordano, se inauguró en octubre de 1985-, para ser destinado posteriormente por el Real Patronato del Museo a la exposición permanente de la obra de Goya y de la pintura del siglo XVIII, aunque esto último no llegó nunca a llevarse a cabo, dado que el 20 de diciembre de 1988 el Ministerio de Cultura acordó con el barón Hans Heinrich von Thyssen-Bornemisza el préstamo, durante un mínimo de diez años, de más de setecientas obras de la colección Thyssen, la creación de una fundación y la cesión gratuita del Palacio de Villahermosa a dicha fundación.

Este acuerdo por el que se le arrebataba al Museo el Palacio de Villahermosa, que habría venido a solucionar la acuciante falta de espacio -como manifestaba en el Boletín del Museo del Prado Alfonso Emilio Pérez Sánchez, director del Prado en ese momento-, volvía a convertir este problema en la preocupación fundamental del Museo, de su Patronato y de su Dirección.

Esta preocupación fue concretándose, y seis años después el Pleno del Real Patronato del Museo aprobó un plan de necesidades del Museo, que manifestaba la urgencia por ampliar las instalaciones de espacios públicos y de exposición, y proponía un concurso internacional de ideas para la ampliación del Museo. El Ministerio de Cultura convocó finalmente el concurso a finales de 1994 y en él participaron mil quinientos veinte equipos de arquitectos de todo el mundo.

Mientras el concurso se iba desarrollando, una proposición no de ley aprobada en el Congreso de los Diputados acordó la incorporación al Museo del Prado del ala norte del antiguo palacio del Buen Retiro, entonces sede del Museo del Ejército, y del solar del claustro de los Jerónimos para la ampliación del Museo.

En 1996 el jurado declaró desierto el «Concurso de Ideas para la Ampliación y Remodelación del Museo del Prado», por lo que el Real Patronato decidió encargar a la Dirección del Museo un plan museográfico elaborado a partir de un análisis profundo de los problemas de espacio del Museo, de las necesidades y exigencias de exposición y visita, así como de las derivadas de la instalación y mejora de los servicios.

Por otra parte, a finales de ese mismo año la Dirección del Patrimonio del Estado adquirió el edificio en el que estaban ubicadas las oficinas de la empresa Aldeasa, situado en la calle Ruiz de Alarcón, incorporándolo al Museo del Prado, donde se instalaron los servicios administrativos del mismo.

Sin embargo, el fallo adverso del jurado no hizo que se abandonara la idea de la ampliación, y en 1998 se firmó definitivamente el convenio con el episcopado para la utilización del solar en torno al claustro de los Jerónimos para la ampliación del Museo del Prado. Tras la firma de dicho convenio se invitó a los diez equipos finalistas del concurso fallado en 1996 a participar en uno nuevo de carácter restringido. Los participantes debían presentar un proyecto del exterior de los edificios de la ampliación, ya que el interior estaba sustancialmente definido. El fallo del concurso, que se hizo público el 10 de noviembre de 1998, recayó en el proyecto de Rafael Moneo.

A principios de 2001 el arquitecto presentó su proyecto definitivo de ampliación del Museo del Prado a la Gerencia de Infraestructuras e inmediatamente comenzaron las obras de ampliación con el desmontaje del claustro de los Jerónimos. 


\section{Organización del Museo del Prado en su periodo constituyente}

En todo caso, transcurridos casi dos siglos de existencia histórica como Museo del Prado, hay que regresar de nuevo al origen de la institución como sede de la más importante colección artística del país y, sin duda, una de las más prestigiosas del mundo en su género. Recuerdo, así pues, que nos habíamos quedado en el punto en el que Fernando VII había manifestado, nada más regresar a España tras su exilio forzado en Francia, el deseo de crear un museo artístico, y cómo, en 1818, se había perfilado ya su definitivo emplazamiento en el entonces deteriorado edificio de Villanueva. Evidentemente, la relación de los cambios habidos en el edificio, someramente descrita en las líneas precedentes, fue debida al incremento progresivo de la colección y a la importancia social que esta fue adquiriendo nacional e internacionalmente. Esto significa que, tras los cambios físicos del Museo, hay que buscar siempre cambios sociológicos y políticos, con sus correspondientes secuelas administrativas.

De esta manera, creado el Museo por un decreto publicado en 1818, la primera pregunta que ahora se impone es la que inquiere acerca de cómo fue su primer sistema de organización diseñado. Pues bien, la primera medida política fue el nombramiento como director del Museo de José Gabriel Silva-Bazán, marqués de Santa Cruz, que a la sazón ocupaba el cargo de mayordomo mayor del Palacio Real. Fue esta una designación que concordaba no solo con la mentalidad del Antiguo Régimen del absolutista Fernando VII, sino también, y casi habría que decir sobre todo, con el hecho indiscutible de ser el nuevo Museo de su particular propiedad. La primera etapa histórica del Prado, la que va desde 1819 hasta 1838, estuvo regida, por tanto, administrativamente, por un criterio señorial, pues todos los directores fueron indefectiblemente miembros destacados de la nobleza española vinculados al servicio palaciego. Además del marqués de Santa Cruz, que apenas si ocupó el cargo un año, entre 1819 y 1820, los tales fueron los siguientes: Pedro de Alcántara TéllezGirón 1, príncipe de Anglona, entre 1820 y 1823; José Idiáquez Carvajal, marqués de Ariza y Estepa, entre 1823 y 1826 y José Rafael Fadrique Fernández de Híjar, duque de Híjar, entre 1826 y 1838. En todo caso, como ya había ocurrido antes con la Academia de Bellas Artes de San Fernando, fundada justo en el ecuador del siglo XVIII, estas prebendas directivas encomendadas a la nobleza no dejaron de estar convenientemente acompañadas por la asesoría técnica de expertos, que no podían ser otros que los artistas. Así, junto a la dirección del Museo otorgada a Santa Cruz, se crearon los puestos de asesor artístico y de conserje mayor-administrador-, que recayeron respectivamente en Vicente López, que era primer pintor de cámara, y Luis Eusebi, un pintor miniaturista que había destacado por su afición y notables conocimientos en historia del arte. En esta primera etapa, José de Madrazo sustituyó a Vicente López, a la muerte de este, en el fundamental papel de asesoría, inaugurando con ello, a continuación, una serie de directores artistas.

Por lo demás, durante esta primera etapa de la vida del Museo, que podemos calificar de constituyente, el sostenimiento financiero de la institución corrió a cargo del «bolsillo secreto» del rey, lo que desdice la leyenda del desinterés o la mezquindad de Fernando VII en relación con este proyecto. El rey no solo aportó el dinero necesario para la remodelación y adecentamiento del edificio, sino que proporcionó una asignación mensual de mantenimiento, a lo que habría que añadir los salarios de la dirección, conserjería y portería, más los restantes gastos de intendencia que también fueron sufragados por el monarca. Por último, y para hacer justicia frente a 
la insidia, también hay que advertir que desde la inauguración del Prado y hasta la muerte del rey, acaecida en 1833, esto es, durante casi quince años, se autorizaron todas las requisas de cuadros, propiedad del rey, allí donde estuvieran emplazados, por no hablar ya de la política de nuevas adquisiciones, que comenzaron con la compra de La Trinidad de José de Ribera, llevada a cabo el 5 de abril de 1820, apenas medio año después de que se abrieran las puertas del Museo, y a expensas del bolsillo del monarca.

De hecho, el incremento de la colección del Museo durante estos primeros quince años de existencia fue espectacular, ya que en la inauguración contaba tan solo con trescientas once pinturas de la escuela española, mientras que en 1827 había almacenados en los depósitos unos cuatro mil cuadros. En cierta manera, el aumento de la colección estaba previsto en el plan original y respondía a la progresiva habilitación de espacio, pero, en todo caso, no hace sino reforzar la idea de un unitario y generoso esfuerzo por parte de Fernando viI para dar relumbre al Museo, que de esta manera no tardó en alcanzar resonancia internacional.

Por otra parte, el naciente Museo se hizo eco de los criterios más avanzados del momento, sin olvidarnos de que la idea misma de abrir un museo público era, por aquel entonces, toda una novedad. En este sentido, resulta elocuente lo publicado en La Gaceta de Madrid como explicación del proyecto, justo la víspera de la inauguración oficial del Museo:

«Entre otros pensamientos de utilidad común que han inspirado al Rey nuestro Señor el ardiente deseo que le anima del bien de sus vasallos, y de propagar el buen gusto en materia de Bellas Artes, fue uno el de formar y franquear al público una copiosa colección de cuadros nacionales y extranjeros por el orden de las diferentes escuelas: establecimiento que al mismo tiempo que hermoseaba la capital del reino, y contribuía al lustre y esplendor de la nación, suministraba a los aficionados ocasión del más honesto placer y a los alumnos de las artes del dibujo los medios más eficaces de hacer rápidos adelantamientos. Destinó S.M. para tan digna empresa la gran copia de preciosas pinturas que estaban repartidas por sus preciosos Reales Palacios y casas de campo y señaló fondos para habilitar los salones y galerías del magnífico edificio del Museo del Prado, donde la colección habría de colocarse. Su augusta esposa, la Sra. D. a María Isabel de Braganza, que Dios goce, movida de los mismos deseos que S.M., se dignó también en proteger y alentar este importante proyecto; y al cabo de año y medio que se ha trabajado en su ejecución, está ya concluida una gran parte de la obra, donde se han ordenado después de bien limpios y restaurados los cuadros de la escuela española, que tanto se distingue aun entre las de otras nacionalidades que han cultivado con gloria las nobles artes; y se continúa la obra para habilitar sucesivamente los salones que deben contener las pinturas de las escuelas italiana, flamenca, holandesa, alemana y francesa; pero no queriendo S.M. dilatar a sus amados vasallos el gusto y la utilidad que pueden resultarles de tener reunidas a su vista las más sobresalientes producciones de los pintores que han honrado con ellas a la nación, se ha dignado resolver desde luego se franquee la entrada al público, y que desde el día 19 del corriente mes de Noviembre esté abierto el Museo por ocho días consecutivos, excepto los lluviosos y en que haya lodos, y en lo restante del año todos los miércoles de cada semana, desde las nueve de la mañana hasta las dos de la tarde». 
No creo que se puedan compendiar mejor que lo expresado en el texto que acabamos de reproducir la razón de ser, el funcionamiento y la finalidad de un museo público, con la única peculiaridad diferencial, respecto a otros modelos contemporáneos, que en el Prado todo dependía del rey: la colección y los gastos de lo que allí se dice sobre la escuela española, subrayando su «diferencia» de las restantes y reivindicando su importancia, pues, por aquellas fechas, reflejaba el mismo criterio romántico destinado a imponerse intencionadamente durante las décadas siguientes, además de fijar precozmente lo que será la personalidad estética del Prado.

Sea como fuere, el Museo se abrió al público en la fecha reseñada y con las trescientas once obras españolas seleccionadas, que fueron dispuestas en la rotonda y galería del norte, la parte entonces ya construida y adecentada del proyecto de Villanueva. Conocemos, por lo demás, cuáles fueron los cuadros seleccionados y exhibidos, gracias a la publicación del catálogo que confeccionó Luis Eusebi. Predominaban los cuadros de Diego Velázquez y Bartolomé Esteban Murillo -más de cuarenta de cada uno-, pero también había veintiocho lienzos de Ribera, quince de Juan de Juanes, seis de Francisco de Zurbarán y, en fin, de casi todos los grandes maestros españoles, como Juan Carreño de Miranda, Juan de Valdés Leal, Alonso Cano, Claudio Coello, Alonso Sánchez Coello, Antonio Palomino, Juan Bautista Martínez del Mazo, etc., siendo muy de destacar la presencia de artistas contemporáneos, como Francisco Bayeu, Mariano Salvador Maella o Luis Paret y Alcázar, algunos de los cuales aún estaban vivos, como José de Madrazo, José Aparicio y el mismísimo Goya.

Respecto a la reacción del público local ante la apertura del Museo, que no fue inmediatamente estruendosa, resulta curioso, sin embargo, constatar que se produjeron críticas bastante parejas a las que se habían ocasionado en Francia con motivo de la inauguración del Louvre, pues se atacaron la disposición cronológica de los cuadros y las deficientes restauraciones a las que habían sido sometidos algunos. Se puede afirmar, por tanto, que el Museo había iniciado su andadura con buen pie y que pronto había de demostrar que ninguna contrariedad iba a impedir su voluntad de seguir avanzando, ni siquiera los tan peligrosos avatares políticos, ya que, al poco de inaugurarse, se produjo la sublevación de Riego, sin que esta circunstancia alterara la vida de la institución, nada más que en el cambio de su director, que ahora fue un simpatizante de los liberales, el príncipe de Anglona, cuyos criterios museísticos no variaron, sin embargo, de los del cesado marqués de Santa Cruz.

\section{Cuando los directores del Prado eran grandes de España}

En realidad, ni este efímero y malhadado episodio liberal, durante el cual el «progresista» Anglona sustituyó al «servil» Santa Cruz, ni la posterior restitución absolutista a cargo de los llamados Cien Mil Hijos de San Luis, que inicialmente comportó la ocupación del puesto directivo por el marqués de Ariza, significaron cambios de orientación en la entonces decididamente ascendente marcha del Museo del Prado. De hecho, la única anécdota reseñable y ciertamente muy reseñable en este periodo de siniestro vaivén político fue la extraña publicación de la traducción francesa del catálogo de Luis Eusebi, ya en la tercera edición. El móvil de tan singular iniciativa fue, sin duda, ese coyuntural aluvión de militares galos que atravesaron la frontera española el 7 de abril de 1823 al mando del I duque de Angulema, Luis Antonio de 
Francia, y que al poco sentaban sus reales en Madrid; mas, en todo caso, también revela el prestigio internacional que había comenzado a tener el Museo del Prado, que, poco después, a comienzos de la siguiente década, mereció elogiosísimas reseñas en algunas de las mejores revistas culturales del país vecino, siendo, además, sus autores, Prosper Mérimée y Louis Viardot. No hay que olvidar tampoco que, durante la década de 1830, la que marcó el triunfo apoteósico del romanticismo, fue cuando se puso de moda la escuela española, cuyo éxito masivo se apoyó en la apertura en París de la mítica Galería Española de Luis Felipe, un museo de oprobiosa memoria para los españoles que permitieron y hasta alentaron la pérdida de algunas de nuestras mejores obras, pero que asimismo sirvió no solo, como se ha dicho, para divulgar el hasta entonces poco conocido y no pocas veces denostado estilo español, sino, sobre todo, para convertir a este en un punto de referencia mítico para las sucesivas vanguardias artísticas parisinas, desde el romanticismo al impresionismo, y eso a pesar de que el célebre museo español no logró sobrevivir mucho tiempo a causa de los avatares políticos que llevaron a Luis Felipe el «rey burgués», al exilio. De cualquier manera, a partir de este momento parecía claro que ningún europeo culto podía prescindir de hacer el obligado tour por España y rendir la correspondiente visita al Museo del Prado.

Pero, volviendo a la historia cotidiana y menuda del Prado, por aquel entonces y hasta el fallecimiento de Fernando VII en constante progresión, apenas sí hay que resaltar la manifestación de dejación de responsabilidad directiva -vulgo, desinterés- por parte del marqués de Ariza, que gustosamente declinó en su función a favor del duque de Híjar, su sobrino, el cual, empero, unánimemente es recordado como uno de los mejores directores que han regido la institución. Quizá resulte más sorprendente la actitud desdeñosa o distanciada de Ariza respecto al Prado, porque no tuvo parangón en esta primera etapa del Museo, durante la cual sus pares nobiliarios, Santa Cruz, Anglona y el recién citado Híjar, todos sin excepción se empeñaron en la labor con notable entusiasmo y acierto, al margen, eso sí, de que las incidencias políticas descritas acortasen o alargasen su mandato. El de Híjar fue con mucho el más dilatado, desde 1826 hasta 1838 y, por consiguiente, el que pudo cosechar mejores resultados, tanto en lo que se refiere al perfeccionamiento del edificio de Villanueva, como a las condiciones reglamentarias y de funcionamiento de la institución y, claro, al incremento notable de los fondos atesorados y expuestos, pero, sin desmerecer un ápice el valor personal de este insigne prócer, hay que apreciar asimismo el contexto favorable en el que se pudo trabajar.

Durante los doce años en los que el duque de Híjar ocupó la dirección del Prado, este, por así decirlo, concluyó su periodo constituyente. Por de pronto, dio el impulso definitivo para consolidar la colección, que es lo esencial en todo museo que se precie, y lo hizo explotando sagazmente la hasta entonces principal fuente de recursos -las colecciones reales-, pero haciéndolo, a veces, mediante vericuetos no hollados, como la recuperación de los fondos depositados en la Academia de San Fernando por el pudoroso Carlos III, entre los que se encontraban algunos de los mejores desnudos de la historia de la pintura -los de Tiziano, Rubens y Durero-, por citar lo más brillante de estas calas y requisas. En esta misma dirección de aprovisionamiento de los fondos artísticos, también fue Híjar el responsable de la primera política de adquisiciones, cuyo broche de oro fue, sin duda, la compra del maravilloso Cristo crucificado, de Velázquez, que conservaba en París la condesa de Chinchón, María Teresa de Borbón y Vallabriga. En otro orden de cosas, Híjar fue asimismo el pro- 
motor de la primera gran instalación de la colección, algo que se tomó tan en serio que requirió incluso el cierre temporal del Museo. No era para menos, porque de lo que se trataba entonces era de colgar setecientos cincuenta y siete cuadros, de los que trescientos treinta y siete eran italianos, trescientos veintiuno españoles y noventa y nueve de las escuelas restantes. Por otra parte, hizo publicar el primer reglamento del Museo, ampliando a dos días por semana la visita pública -los miércoles y los sábados-, y dando otras instrucciones varias orientadas a proteger la buena conservación de los cuadros.

Se podía seguir haciendo recuento de otras muchas cosas positivas derivadas de la gestión de Híjar, pero, como antes señalé, también es verdad que se benefició de un ambiente decididamente favorable, que podemos describir como el de una autocracia en la que el autócrata es un entusiasta partidario del asunto y el asunto en cuestión no es polémico, encima, para nadie. En los sucesivos años, España frecuentaría los autócratas, pero, desdichadamente, sin que su supuesto amor por el Museo del Prado traspasase jamás los límites de la retórica. Con la dirección de Híjar, así pues, no solo concluyó una primera etapa histórica de la institución, la del régimen absolutista de Fernando viI, sino también, quizá, en la que nada parecía poder lastrar la buena marcha del Museo.

\section{La muerte de Fernando VII amenaza la supervivencia del Prado}

Nada más morir Fernando vil comenzaron las dificultades para el Museo del Prado, algunas de tal envergadura que amenazaron gravemente la continuidad del mismo, como, sin ir más lejos, la inclusión de la colección entre los bienes sujetos a la libre disposición testamentaria, lo que implicaba su reparto entre los herederos y, por tanto, su fatal dispersión. Se llegó incluso a hacer el correspondiente inventario y tasación, pero, afortunadamente, primero, gracias a un aplazamiento en la ejecución de las mandas testamentarias en función de la minoría de edad de Isabel II, y, después, gracias a la resolución de una comisión que sensatamente dictaminó compensar económicamente a las restantes partes afectadas, se pudo salvar la colección y el Museo. Así y con todo, el peligro no quedó por completo conjurado hasta que, en 1865, no se vinculó el Museo al patrimonio de la Corona, lo que, en términos legales, significaba prácticamente su nacionalización.

Por lo demás, la inmediata guerra civil carlista también generó no pocas zozobras, directas e indirectas, al Museo, que comenzó a sufrir recortes presupuestarios y se vio preterido. Más allá de estas apreturas materiales, consecuencia directa del caos bélico, no deja de ser paradójico que el fin del absolutismo político supusiera un parón para una institución pública como era el Museo del Prado, aunque aún no estuviera clara su titularidad. De todas formas, lo que sí trajo el nuevo orden político fue un cambio administrativo, que se reflejó directamente en el Museo al sustituirse a los miembros de la nobleza en la dirección por los artistas, que hasta entonces eran meros asesores. Se inició de esta manera la segunda de las tres etapas, que, en este campo, se han producido en la historia del Prado hasta la actualidad: la etapa de los directores artistas, la más dilatada en el tiempo, pues duró desde 1838, fecha en la que el duque de Híjar tuvo que ceder su puesto, con bastante resentimiento, por cierto, al pintor José de Madrazo, hasta 1960, el año en que murió Fernando Álvarez de Sotomayor, siendo inmediatamente sustituido por el historiador del arte Francisco 
Javier Sánchez Cantón. La Dirección del Museo del Prado fue, por consiguiente, ocupada por tres cuerpos o profesiones diferentes: miembros de la nobleza, artistas e historiadores del arte.

Pues bien, dejando de lado la excepcional presencia de los aristócratas, que se produjo en nuestro país tanto por pertenecer la colección al rey, como por la artificial prolongación del Antiguo Régimen, la discusión acerca de quiénes podrían desempeñar mejor el cargo de directores de los museos, si los artistas o los historiadores, armó un considerable ruido polémico a lo largo de casi todo el siglo XIX, y en cierta medida, aún dista de haber quedado por completo zanjada. Y es que el fundamento de la polémica tiene que ver con la ambigua naturaleza del arte mismo, si se le considera desde el punto de vista de la sensibilidad o como documento histórico. Como quiera que, por otra parte, se conciba como se conciba el Museo, no se le puede desligar de la naturaleza de los objetos que atesora, cualquier visión parcial resultará, en alguna forma, limitadora. Por eso, carecen de sentido los planteamientos corporativos en esta cuestión, cuya resolución ideal estará siempre de parte de, por así decirlo, las criaturas «mixtas»; esto es: artistas con una excelente formación histórica o historiadores dotados de sensibilidad artística, por citar las dos profesiones que tradicionalmente se han disputado más ese privilegio. Hay que señalar que, dada la complejidad organizativa y administrativa que ha ido adquiriendo la institución museística, que ya no se limita solo a la conservación y el estudio de las obras de arte, habría que unir a esas dos vertientes, la artística y la histórica, una última de gestión.

\section{La hora de los artistas}

Pero si he hecho un alto para considerar esta cuestión, aprovechando la anécdota de cómo los artistas sucedieron a los aristócratas en la dirección del Museo del Prado a finales de la década de 1830, no ha sido solo para advertir de que, durante estas dos primeras etapas, hubo por igual buenos y malos directores, fuera cual fuera su condición o profesión, como iba a ocurrir cuando le tocara el turno a los historiadores del arte universitarios. En realidad, la historia nos ha enseñado que la suerte de un museo artístico no la dictan sus directores y, aún menos, en función de su formación profesional, sino la sociedad en la que están ubicados y a la que se deben y, sobre todo, de la que dependen. En este sentido, es cierto que los políticos, representantes en teoría cualificados de la voluntad social, pueden coyunturalmente estimular la atonía de esta o encauzarla, pero nadie puede crear un buen museo al margen o en contra de la sociedad en la que se sustenta.

La historia del Museo del Prado es, desde luego, un muy vivo ejemplo de lo antes expuesto. Durante el transcurso de su historia, no solo hubo en España regímenes monárquicos y republicanos, sino toda suerte de contingencias políticas, desde cambios de dinastías a gobiernos absolutistas, constitucionalistas, revolucionarios, de derechas, de izquierdas, etc., pero ninguno tuvo el poder para cambiar el nivel de la sociedad como por ensalmo. Es cierto que el museo público tiene su razón de ser y su caldo de cultivo ideal en los regímenes democráticos, más ello en la medida en que se es comparativamente más consciente de que las instituciones culturales no se pueden construir, ni mucho menos prosperar, de espaldas a la sociedad. En cierta manera, esa es la grave cuestión de fondo que desde 1838 asedia al Museo del Prado. 
Pero, volviendo a la etapa que se inició con el nombramiento del pintor José de Madrazo, que ocupó el cargo hasta 1857, durante casi veinte años, una de las direcciones más prolongadas, excepciones hechas de la de su hijo Federico que estuvo al frente de la institución durante veintidós años, y la de Fernando Álvarez de Sotomayor, que llegó a los treinta, si bien cada uno de ellos en dos periodos diferentes, cabe observar algunas orientaciones positivas desde el punto de vista museográfico, orientaciones que, además, dada la permanencia en el cargo, así como el casi asentamiento dinástico de la familia Madrazo en el Prado, se consolidarán y hasta se convertirán en una suerte de «estilo» que marcará la institución. En este sentido, la amplia formación cultural y el cosmopolitismo de José de Madrazo, que vivió de lleno los ambientes refinados de Roma y París en momentos bastante cruciales, fueron bazas trascendentales. Un dato muy elocuente al respecto fue la solicitud que cursó al Musée du Louvre para que le remitiesen una copia del reglamento interno de dicha institución, lo que indica que José de Madrazo ya se preocupaba de dotar al Prado con una estructura administrativa y un catálogo puestos acorde con una gestión moderna. Al poco, de hecho, presentó una propuesta de plantilla, en la que, además de director, estaban un secretario-interventor, dos restauradores, tres ayudantes de restauración, un forrador-moledor con ayudante, un conserje, once porteros y tres plantones o guardias para las entradas. Hizo también el cálculo de las correspondientes retribuciones, resultando el coste total de la plantilla la suma de 118080 reales anuales. Importa saber que no logró su propósito y, lo que es peor, que, cuando, tras ímprobos esfuerzos, lograba avanzar un paso en esa dirección, se veía inmediatamente superado por dos pasos de retroceso. No es de extrañar que esta insufrible falta de dotación padecida por el Museo acabara por desanimarle y fuera la causa directa de su dimisión, el 30 de marzo de 1857, después de estar bregando por espacio de diecinueve años. Más aún: ocupando ya la plaza de director su hijo Federico de Madrazo, tras el breve interregno de Juan Antonio Ribera, el 17 de noviembre de 1866 fue publicado un real decreto que reducía la plantilla del Museo a mínimos miserables, además de rebajárseles el sueldo a los supervivientes. Era, así pues, la primera vez, pero desgraciadamente no la última, que se ponía de manifiesto la equivocación de la administración española entre «edificio», «colección» y «museo»; esto es: entre «materia» $\mathrm{y}$ «vida» de un museo. $\mathrm{Y}$ es que de poco sirve un magnífico contenedor y un extraordinario contenido, si luego se escatiman los recursos de personal y mantenimiento que hacen que la institución cumpla dignamente su función. En definitiva: que el Prado tuvo y sigue teniendo una de las más extraordinarias colecciones artísticas que atesorarse pueda, pero durante mucho tiempo le faltaron esos recursos de toda índole que podrían haberle hecho acreedor al título de gran museo.

Significativamente, José de Madrazo no encontró resistencias semejantes en los restantes campos en los que se propuso actuar, como la terminación de lo que aún quedaba por construir del proyecto de Villanueva -el cuerpo central, en forma basilical, que pudo inaugurarse en 1853, según la interpretación del arquitecto Narciso Pascual y Colomer-; la notabilísima incorporación de obras maestras, resultando espectacular la que se llevó a efecto a partir de las entonces soberbias y mal cuidadas de El Escorial; o, en fin, la nueva instalación de la colección, que, tanto por las nuevas y muy notables incorporaciones como por la sensata revisión de lo amontonado en los almacenes, supuso un cambio cuantitativo y cualitativo de proporciones sorprendentes. La nueva instalación fue inaugurada el 27 de abril de 1839, contando con seis nuevas salas de pintura y una de escultura, y, si hacemos caso de lo que se re- 
gistraba en el catálogo del Museo en su edición de 1843, resulta que había expuestos mil ochocientos treinta y tres cuadros, más las esculturas y relieves, y, sobre todo, el maravilloso conjunto llamado «Tesoro del Delfín», por cuya posesión peleó José de Madrazo denodadamente. Todo esto indica que, respecto a las existencias de 1828, el Prado había prácticamente doblado el número de obras de arte en exhibición y que estas estaban además presentadas en unas condiciones de limpieza e iluminación desconocidas hasta entonces.

Desde luego, hubo otros mil detalles comparativamente menudos que enaltecen la gestión de José de Madrazo y su modernizadora visión de lo que debía ser el Museo, hasta el punto de que, como antes sugerí, creó un «estilo». Se ironiza, a veces, a costa de lo que la perdurabilidad de este estilo pudiera tener que ver con la entronización de su estirpe familiar en la historia del Museo, no solo porque, como se ha dicho, su hijo Federico ocupara el cargo de director también por espacio de décadas, sino por la relación habida con la institución por otros miembros de la familia. No obstante, y a pesar de que siempre hay borrones que maculan una trayectoria, sobre todo cuando esta se extiende tanto a lo largo del tiempo, un balance ponderado de lo que supuso el paso de los Madrazo por el Prado arroja un saldo más que positivo.

Así las cosas, se podría dar un salto en la historia del Museo del Prado hasta fines del siglo XIX, cuando aún regía la institución Federico de Madrazo, pues falleció este siendo director en 1894, sin registrar ningún cambio sustancial, salvo el importantísimo ya reseñado de la «nacionalización» de la colección, o el que vamos a tratar a continuación, de pareja trascendencia, aunque no de tan benemérita resolución. $\mathrm{Me}$ refiero al peliagudo asunto del «Museo de la Trinidad» y su fusión con el del Prado, que tuvo efecto legal por el correspondiente real decreto de 22 de marzo de 1872.

\section{El Museo de la Trinidad y su fusión con el Museo del Prado}

El Museo Nacional de la Trinidad, abierto al público el 24 de julio de 1838, fue creado como consecuencia de la célebre ley de Desamortización de los bienes de las órdenes religiosas, decretada, en 1835, por el ministro de Hacienda, Juan Álvarez Mendizábal. A causa de esta ley, el Estado se halló como imprevisto tutelador de una fabulosa suma de obras de arte desamparadas. Hay que tener en cuenta que la Iglesia $\mathrm{y}$, en especial, las órdenes religiosas habían constituido una de las fuentes privilegiadas de mecenazgo artístico durante los siglos anteriores. El caso es que, abandonados cientos de conventos e iglesias, el peligro de destrucción o expolio de una parte sustancial del patrimonio artístico creó una justificada alarma social. En consecuencia, se nombraron comisiones de salvamento y, como lógico colofón, se ideó crear un museo en el que se pudieran depositar y visitar estos bienes. Se eligió para tal efecto el exclaustrado convento de la Trinidad, cuya puerta principal se abría a la céntrica calle de Atocha, pero que también comunicaba con la calle Relatores y la plaza del Progreso, un convento en el corazón mismo de Madrid. La primera requisa supuso un conjunto de novecientos cuadros, que no hizo sino aumentar por la misma vía de provisión o por otras, como la incautación de la colección del infante Sebastián Gabriel de Borbón y Braganza. De esta guisa, hubo una primera inauguración oficial del Museo Nacional de la Trinidad, tal y como se dijo, el 24 de julio de 1838, y otra, años más tarde, el 2 de mayo de 1842. 
Por las fechas y el ambiente político que entonces se respiraba en España, no puede descartarse que el proyecto de este Museo Nacional no estuviera complementariamente cargado de una cierta intención de competir, desde la nueva perspectiva del nuevo mecenazgo oficial, patrocinado por el Estado, con el Museo del Prado, que no en balde seguía siendo el Museo Real de Pinturas, iniciativa y propiedad de la familia real. Sea como sea, el Museo de la Trinidad se puso en marcha con una colección fundamentalmente de pintura religiosa, de valor muy desigual, pero, con todo, contando con nombres relevantes de los mejores maestros de la pintura española. El insigne historiador Gregorio Cruzada Villaamil, que llegó a ocupar la subdirección del Museo, publicó, en 1865, un ejemplar catálogo de lo más excelente entre lo conservado en dicha institución -de las mil setecientas treinta y tres obras existentes seleccionó quinientas noventa y nueve, además de incluir los setecientos sesenta cuadros de pintores del XIX que habían sido premiados en las Exposiciones Nacionales de Bellas Artes-, catálogo que nos da cumplida cuenta tanto de la cantidad, como, sobre todo, de la calidad de lo allí atesorado.

Ahora bien, si el Museo del Prado, a pesar de la directa tutela real y del notabilísimo prestigio internacional que había alcanzado, debió padecer las dificultades que antes hemos descrito, no hace falta ser muy imaginativo para inferir las que sufrió el Museo Nacional de la Trinidad prácticamente desde su inauguración o inauguraciones. En realidad, por escatimársele hasta lo más elemental, se llegó a discutir hasta su sede, que fue destinada, sin solución alternativa para el Museo, a Ministerio de Comercio, Instrucción y Obras Públicas. Dadas las circunstancias, no resulta nada extraño que, al margen de que así lo recomendase en un apasionado folleto el erudito Vicente Poleró, finalmente se acordase la fusión del Museo de la Trinidad con el del Prado en la fecha anteriormente consignada del 22 de marzo de 1872. En todo caso, no puedo dejar de recoger aquí las críticas que a posteriori suscitó y, en algún caso, todavía suscita dicha decisión, aunque personalmente me parecen infundadas. En primer lugar, porque los hechos mismos demostraron que mal podía hacerse cargo un país de dos museos cuando se había demostrado que el mantenimiento elemental de uno solo le venía grande, pero, también, en segundo, porque la estrategia inicial del salvamento del patrimonio artístico por parte de una nación pobre y desunida se basa en la concentración. Por lo demás, el hecho de que, dada la irresponsable incuria de la Administración y de la sociedad españolas en relación con estos temas, el efecto de la fusión fuera precisamente el contrario, como enseguida explicaremos, no solo no quita bondad al principio, sino que, aún menos, garantiza que el mantenimiento contra corriente del Museo de la Trinidad, si ello hubiera sido posible, deparara una mejor suerte que la que padecieron los cuadros en él almacenados.

En fin, que lo que ocurrió tras la decretada fusión no fue sino el comienzo de una alocada dispersión de fondos por toda la geografía española, recalando en los sitios más peregrinos y en las peores condiciones que imaginarse pueda. La razón era bien sencilla, pues ¿de qué forma habría de recoger el Museo del Prado ese súbito aluvión de millares de obras, cuando, a la sazón, apenas sí contaba con espacio disponible para exhibir y almacenar las propias? La causa del reprobable desastre no se debió, en todo caso, a la iniciativa de fusión, sino a no haber previsto la necesidad de dotar con nuevos espacios al Prado, o, si esto circunstancialmente no era posible, a no haberle dotado con los medios correspondientes para haber procedido a una muy bien pensada política de depósitos. Que esto es así lo demuestra el hecho de que hubo de 
transcurrir más de un siglo y promediar un verdadero escándalo para que se iniciara la adecuada corrección del dislate.

Por tanto, lo peor fue que el reparto de depósitos se hiciera sin garantizar ni el porqué, ni el cómo, ni siquiera el para qué, con lo que, enseguida, cualquier personajillo, circunstancialmente investido con la mínima autoridad, pudo retirar fondos del Prado prácticamente para lo que le viniese en gana, y sin que el Museo tuviera el menor control efectivo acerca de la situación en la que quedaba la obra prestada. Hay que añadir que este nefasto hábito arraigó con fuerza en la Administración española, fuera cual fuera el régimen político del momento, y que, increíblemente, no se tomaron cartas en el asunto hasta prácticamente la segunda mitad de la década de 1970, cuando, ya iniciado el proceso de la transición democrática, y luego de ser aireado el asunto por la prensa y de intervenir un juez, se intentó el inventario, la localización y la revisión de estos depósitos. Alfonso Emilio Pérez Sánchez, que participó directamente en este proceso, publicó algunos ejemplos escalofriantes de la suerte padecida por estos depósitos, además de constatarse la desaparición de unos pocos ejemplares. Todavía en 1969, Diego Angulo Íñiguez, entonces director del Museo del Prado, publicó una crónica histórica de este con motivo de la celebración en ese mismo año del ciento cincuenta aniversario de la institución, crónica en cuya parte final, además de señalar la imperiosa necesidad de una adecuada climatización que preservara a los cuadros de la contaminación y de requerir un drástico aumento del número de celadores, sin que -según allí decía- ninguna de las dos iniciativas obtuvieran respuesta positiva por parte del Ministerio, también trataba el aún no resuelto problema de los depósitos. Angulo afirmaba literalmente:

«Parece razonable que la mayor parte de los cuadros del Museo que se encuentran distribuidos por toda España en edificios donde solo realizan una función decorativa y de los que solo disfrutan pocas personas, se redistribuyesen formando colecciones sistemáticas que pasasen a ser expuestas en salas a ellas dedicadas en los principales museos, durante un periodo de un corto número de años, y donde fueran reemplazadas periódicamente previa revisión y restauración por la Dirección del Prado y su taller de restauración, por las expuestas en los otros museos».

Es cierto que más de tres décadas después de lo mandado por Angulo el Museo del Prado ha hecho o está en vías de hacer casi todo lo que este insigne profesor reclamaba en el citado artículo, pero medítese, a propósito de este asunto, lo rápido que se destruye y lo lento que resulta corregir y reparar lo destruido: ¡un siglo de incuria y dispersión y más de tres décadas para reconducir la situación!

En 1999 se inició el Plan General de Revisión Sistemática de los depósitos del Museo del Prado en otras instituciones, pero aun así dos años después el Tribunal de Cuentas recomendó al Museo del Prado que efectuara un esfuerzo por mejorar el control de sus fondos artísticos, en especial los que se hallaban en depósito en otras instituciones, por las dificultades para conocer la existencia real de algunas obras, su ubicación o su conservación. El celo para gestionar las obras del llamado «Prado disperso» se ha ido intensificando desde entonces, siendo un hito fundamental en esta labor la presentación, el 25 de abril de 2003, de la Casa de los Águila, en Ávila, como centro adscrito al Prado, edificio en el que, tras su remodelación y rehabilitación, se centralizarán la gestión y conservación de las obras del Museo del Prado 
depositadas fuera del mismo, además de ser el centro de producción y gestión del programa de exposiciones «Prado itinerante».

\section{El Museo del Prado durante la Restauración}

Mas volviendo a retomar el hilo histórico donde lo dejamos, la rápida y convulsa sucesión de acontecimientos políticos que, desde el destronamiento de Isabel II hasta la restauración en el trono de su hijo Alfonso XII, agitaron a España, no supusieron otros cambios para el Museo del Prado que los ya reseñados, pero agravaron su estado de penuria. Así, cuando Federico de Madrazo retornó al puesto de director que había tenido que abandonar trece años antes, en 1868, por causas políticas, se encontró con que, a causa de la endémica penuria de medios que se venía agravando desde que su padre dimitió del mismo cargo, allá por 1857, el Museo del Prado se había convertido en una especie de patio de monipodio, con familias enteras que tenían instalada su vivienda allí y otros peligrosos disparates de este jaez. A lo que se vio, no supo o no pudo poner remedio eficaz a la situación, de manera que, diez años después de su reingreso, se organizó un curioso escándalo, que merece un comentario aparte.

El 25 de noviembre de 1891 el periódico El Liberal publicó un reportaje, firmado por Mariano de Cavia, con el siguiente escalofriante titular: «La catástrofe de anoche: España está de luto. Incendio en el Museo de Pinturas». Aunque la noticia era evidentemente falsa, el sagaz periodista daba pelos y señales de la catástrofe e indicaba cómo esta se había producido precisamente a causa de las lamentables condiciones que antes hemos señalado y cómo, una vez desencadenada, nada había podido hacerse para pararla. A resultas de la verosimilitud del relato, muchos madrileños acudieron, alarmados, al lugar de autos, sin que la comprobación directa de la falsa alarma disipara su preocupación, que era el objetivo buscado por Mariano de Cavia. De manera que lo que se había consentido durante años, con total indiferencia por parte de la Administración y de la sociedad misma, produjo repentina contrición, aportándose de inmediato las medidas correctoras más urgentes. Desde este punto de vista, es innegable que el artículo de Mariano de Cavia merece el abundante elogio que tradicionalmente ha suscitado, pero también debe hacernos pensar en que haga falta enarbolar falsas o verdaderas tragedias para que los políticos y la opinión pública presten atención a lo que resulta cotidianamente evidente para cualquier visitante del Prado. Y es que mientras el Museo necesite titulares de medios de comunicación de masas, mal le irán las cosas a nuestra principal institución artística.

Sea como fuere, con el Museo definitivamente nacionalizado, pocos fueron los cambios administrativos, desde fines del siglo XIX hasta mediada la década de 1990 . Tres fueron los más relevantes. El primero de ellos la creación de un Patronato en 1912, que adquirió plena autonomía en 1927, lo que le dotaba de la capacidad de administrar, poseer y adquirir bienes de todas clases en lo referente a la administración, enriquecimiento y mejora del Museo. Ni el advenimiento de la República ni la Guerra Civil ni la instauración de la Dictadura del general Franco produjeron cambios significativos en la estructura del Museo, no existiendo nuevas reglamentaciones hasta que en 1968 se produjo el segundo de los cambios. Ese año el Patronato del Museo del Prado pasó a depender del recién creado Patronato de Museos Dependientes de la Dirección General de Bellas Artes, que era el encargado de gestionar la mayor parte de los museos españoles; por lo que el Prado perdió su autonomía y pasó a 
ser controlado enteramente desde la Administración. Esta situación se mantuvo hasta que en 1985 el Museo recobró su autonomía al convertirse en organismo autónomo.

También se podría reseñar a este respecto, pero desde una perspectiva más anecdótica, el cambio en la extracción profesional de los directores a partir de 1960, fecha en la que muere, siendo director del Prado, el pintor Fernando Álvarez de Sotomayor, y es sustituido en el cargo por el historiador del arte universitario Francisco Javier Sánchez Cantón. Desde entonces y hasta la fecha, los sucesivos directores han sido casi todos, en efecto, historiadores del arte universitarios -Diego Angulo, Xavier de Salas, José Manuel Pita Andrade, Alfonso E. Pérez Sánchez, Felipe Vicente Garín, Francisco Calvo Serraller, Fernando Checa, Miguel Zugaza- y, cuando no, el musicólogo Federico Sopeña o el arqueólogo José María Luzón, asimilables a aquéllos por su competencia científica y probada experiencia museológica.

Por lo demás, con la creación de un patronato se pretendía tutelar la institución mediante el consejo independiente de destacadas personalidades de la cultura y la sociedad españolas, una forma de implicar o interesar en la buena marcha del Museo a la denominada «sociedad civil». En esta misma dirección, aunque en este caso, al margen por completo de la Administración, también conviene resaltar la creación de la Fundación Amigos del Museo del Prado, que es una fundación privada, al estilo de otras que hoy proliferan por todo el mundo, cuyos miembros aportan desinteresadamente fondos para la adquisición de nuevas obras para la colección o el fomento de actividades diversas que el Museo no puede atender con sus siempre limitados recursos. La Fundación Amigos del Museo del Prado se constituyó en diciembre de 1980, impulsada por Enrique Lafuente Ferrari junto con un grupo de representantes de diferentes sectores de la sociedad. Su propósito, según está reflejado en sus estatutos, es «todo lo relacionado con la promoción, estímulo, apoyo y desarrollo de cuantas acciones culturales, educativas y de otra índole tengan relación con el museo, para ayudar a su misión y a sus actividades, y para incrementar sus colecciones, su conocimiento, su difusión nacional e internacional, y su integración en la sociedad». Desde su constitución la Fundación ha cumplido y sigue cumpliendo con creces sus propósitos, poniendo en marcha y llevando a cabo múltiples iniciativas, como la donación de obras al Museo, el patrocinio de exposiciones, la organización de cursos, viajes, visitas guiadas y ciclos de conferencias, entre otras actividades, y una destacada labor de publicación de numerosas obras relacionadas con el Museo.

El convertir el Museo del Prado en organismo autónomo buscaba, por su parte, una mayor agilidad en la gestión del mismo, algo esencial cuando el crecimiento del personal que trabaja en la institución ha superado ya los quinientos individuos, por no hablar de la multiplicación de los servicios y, en fin, la complejidad del presupuesto.

La vuelta de la autonomía vino acompañada por la restauración del Patronato, pero no fue esta la última modificación en el régimen del Museo; así, el Gobierno en 1996 reformó el régimen interno del Museo del Prado con el objetivo de adecuarse a los nuevos tiempos y a los cambios que traería consigo la futura ampliación del Museo. De este modo el Real Patronato vio ampliados sus cometidos y atribuciones y al año siguiente aprobó el Plan Museográfico, en el que se establecían unos criterios de uso de los edificios y de reordenación de las colecciones que sirvieron de base para el proyecto de ampliación del Museo que tratamos con anterioridad. Posteriormente, en 2001, el Patronato acordó que el Museo del Prado modificase su estructura jurídica, 
pasando de ser organismo autónomo a ente público para lo que era necesario «una norma de rango de ley» que estuviese vigente y operativa en 2002.

Pero la modificación más importante llegó el 26 de noviembre de 2003 con la publicación en el Boletín Oficial del Estado de la ley que regulaba el Museo Nacional del Prado. Esta ley convirtió el Museo Nacional del Prado en un organismo público de carácter especial, lo que le dotaba de mayor autonomía y le otorgaba mayor flexibilidad a la hora de plantear las actuaciones necesarias para alcanzar sus fines y mayor autosuficiencia en la gestión.

El seguimiento del curso histórico del Museo del Prado desde su fundación ha puesto en evidencia cómo la suerte de este va estrechamente ligada a la propia historia del país, que no ha sido precisamente un modelo de estabilidad. De hecho, el Museo ha vivido la mayor parte del tiempo acosado por un peligro potencial casi constante, y asombra en función de ello, el que apenas haya sufrido daños de consideración, al margen de los ya reseñados de la descuidada dispersión de una parte de sus fondos. Téngase en cuenta que, en alguna ocasión, tuvo que hasta expatriarse, como acaeció durante la guerra civil de 1936-1939, cuando, para evitar el efecto letal de los bombardeos sobre Madrid, se trasladó lo más importante de la colección primero a Valencia y poco después a la ciudad suiza de Ginebra. Afortunadamente, tampoco el Museo ha sido jamás castigado por ninguna catástrofe natural ni accidente realmente grave, como robo o destrucción de alguna de sus piezas maestras, o como ese incendio imaginario que denunció en su momento Mariano de Cavia. En 1918, eso sí, se advirtió la desaparición de parte de las alhajas del Tesoro del Delfín, pero ni este episodio ni otros similares han ocasionado nada que se parezca a lo producido por la incuria políticoadministrativa, como fue el caso flagrante, antes ya denunciado, de la dispersión incontrolada de parte de sus fondos, una cuestión hoy ya casi por completo solucionada.

Lo que se hizo al respecto fue, aunque no sin que antes mediasen denuncias en la prensa y una instrucción judicial, un inventario de lo prestado, procediéndose a su localización exacta, análisis de la situación de cada obra encontrada y, si el caso lo requería, levantamiento provisional o definitivo del correspondiente depósito en aras de garantizar su conservación. A continuación, se procedió a poner en práctica una política racional de depósitos en la misma línea que demandaba, allá por 1969, con motivo del ciento cincuenta aniversario de la institución, el que entonces era su director, Diego Angulo; esto es, si recordamos el escrito de este, antes reproducido, que se preocupase que los tales depósitos afluyeran prioritariamente a lugares abiertos a la contemplación pública y donde estuvieran convenientemente resguardados, lo que significa, en una palabra, que se prestasen prácticamente solo a museos. Aunque todavía queda lejano el cumplimiento de este objetivo, pues no pocas veces la dirección del Museo se topa con la resistencia numantina de las instituciones oficiales implicadas, al menos actualmente no solo se tiende irremisiblemente a ello, sino que, además, mientras tanto, el control sobre los depósitos es total y continuado. Por otra parte, el Museo del Prado, con sus tres mil obras esparcidas por todo el territorio del Estado español, puede enorgullecerse de ser uno de los museos nacionales más descentralizados del mundo, ya que no solo se limita a esta generosa distribución de fondos, que, a veces, constituye el cuerpo fundamental de la colección de no pocos museos de las diversas autonomías, formando con ello lo que expresivamente se conoce, ahora con sentido positivo, como «Prado disperso», sino que también lleva a cabo una política de exposiciones temporales de carácter itinerante, que recorren casi todo el país año tras año, política que recibe la denominación de «Prado itinerante». 


\section{Los reyes españoles como mecenas de las artes}

Llegados a este punto, conviene comentar también algo a propósito de la colección del Museo del Prado, que actualmente cuenta con más de veinte mil obras de todo tipo, cifra verdaderamente espectacular, sobre todo si se recuerda que se inauguró con tan solo trescientos once cuadros de pintura española. Pues bien, como se ha comentado, el origen y la parte cualitativamente esencial de esta colección procede de lo atesorado por los reyes españoles a lo largo de los siglos, lo que significa que el Prado cuenta con lo adquirido en su momento por monarcas como, entre otros, Pedro IV de Aragón, el Ceremonioso, Alfonso v de Aragón, el Magnánimo o la mismísima Isabel, la Católica a través de cuya testamentaría sabemos que legó al morir trescientas cincuenta pinturas entre otros muchos objetos artísticos. De todas formas, a partir del siglo XVI, cuando se difundió por toda Europa occidental el modelo cortesano de colección creado en la Italia del Renacimiento, este asunto alcanzó en nuestro país unas proporciones formidables, ya que desde Carlos I hasta Fernando vII, no hubo titular de la Corona española que no prestase atención al coleccionismo artístico.

Desde luego, el impulso dado al tema por la dinastía de los Austrias españoles no encontró parangón en Europa, como así lo acreditaron principalmente Carlos I, Felipe II y Felipe IV, a quienes el Museo del Prado debe una parte principal de lo mejor de sus actuales fondos; pero ello no quita mérito a lo ulterior llevado a cabo por la dinastía borbónica, sobre todo si se piensa que lo realizó en unos momentos históricos mucho menos venturosos que los anteriores. En todo caso, es a partir de Carlos I cuando, como antes se apuntó, se planteó un ideal moderno de colección artística, lo que posteriormente fue refrendado por su hijo Felipe II, no solo continuador del criterio y el gusto paternos, sino también el primero en preocuparse por buscar un buen emplazamiento estable para lo atesorado, lo que significó desplegar la colección, hasta entonces ubicada en el Alcázar madrileño, en nuevos lugares, como el palacio de El Pardo y el Real Monasterio de San Lorenzo de El Escorial, donde se llegaron a reunir más de un millar de pinturas.

Pero si el gusto de estos primeros Austrias españoles, formados en la elegante corte borgoñona, cuya exigente etiqueta adoptaron, fue refinadísimo, aún quizá más importante fue la pasión demostrada por el arte, una pasión de la que tenemos cumplida cuenta, más allá de la mera acumulación de objetos, en el ansia compulsiva que pusieron para conseguir lo que amaban, tal y como, por ejemplo, nos revela la correspondencia conservada que padre e hijo cruzaron con Tiziano. Este dato tiene más importancia, insisto, que lo que asépticamente se puede deducir del crecimiento material de la colección, según se reflejó en los correspondientes inventarios testamentarios, ya que será la pasión la que marcará con una impronta indeleble el sello del gusto español, tal y como, por extensión, se le reconoce a la por eso así llamada escuela española y, naturalmente, tal y como todavía hoy se puede distinguir la personalidad del Museo del Prado.

\section{Una colección con marcada personalidad}

El Museo del Prado posee, efectivamente, y dicho con toda rotundidad, una de las colecciones con más personalidad entre las existentes hoy en todo el mundo, algo que implica virtudes, pero también defectos, y que a veces atesora de un autor o de 
una escuela hasta el exceso, mientras que sus ausencias son asimismo clamorosas. La razón es que el Museo del Prado, quizá fascinado por ese signo pasional que marcó lo más feliz de su colección original, renunció al ideal de colección enciclopédica, que es la que pretende, según criterios heredados de la Ilustración, poseer ejemplos representativos de todo lo artísticamente significativo que se ha producido a lo largo de toda la historia del arte, procurando, además, que el conjunto sea lo más equilibrado posible. El Prado, sin embargo, resulta definitivamente insuperable en lo que tiene de bueno y casi está ya obligado a renunciar a rellenar sus estruendosas lagunas. Bueno o malo, en cualquier caso, esto no solo le distingue, sino que distingue asimismo la sensibilidad artística nacional, ya que parece concebido como una colección hecha a la sombra del gusto artístico español, una colección que refleja eso que los románticos les daba por llamar el «espíritu del pueblo». Por lo demás, es probable que la consolidación tan cerrada de ese gusto artístico español fuera concebida por el progresivo aislamiento internacional de nuestro país a partir del siglo XVII, pero el desencadenante original del mismo fue esa forma pasional de coleccionar que implantaron los primeros Austrias y de la que pronto se contagiaron los principales nobles cortesanos españoles. En este sentido, solo así se entiende la pasión que por Tiziano y, en general, por los pintores venecianos demostraron Carlos I y Felipe II, pero también, más exótica y anacrónicamente, la que este último sintió por El Bosco, o, en fin, la que sucesivamente acreditaron Felipe Iv por Rubens y Velázquez, y, dando un salto en el tiempo, Carlos Iv por Goya.

Así que, sean cuales sean sus ausencias, a veces dictadas por la historia y otras por ese gusto refractario que nos hizo perder la oportunidad en su momento, ¿quién, cabe preguntar, puede, con todo, aspirar a conocer, no ya la escuela española, sino la veneciana o la flamenca, sin visitar el Museo del Prado? ¿Quién puede aproximarse a figuras singulares de extraordinario porte, como Tiziano, Rubens, Velázquez o Goya, si no gira frecuentes visitas al Museo madrileño? Y es que el Museo del Prado, genio y figura, refleja como ningún otro una tradición histórica, un gusto y, en efecto, una pasión, esa pasión que ha llevado a afirmar al pintor español Antonio Saura que el Prado es, si no el más extenso, sí el más «intenso» de entre todos los museos.

Mas si el Museo del Prado recibió un fuerte espoleamiento a fines del siglo XIX, no solo al socaire de esa denuncia del falso incendio que eficazmente aireó Mariano de Cavia, sino también aprovechándose del clima de regeneracionismo nacional, propiciado en esa misma década por la pérdida de las últimas colonias ultramarinas, aún debió sufrir posteriormente otras agitaciones y polémicas dirigidas asimismo a cubrir muchas deficiencias estructurales y funcionales. De hecho, desde que comenzó el siglo xx se puede percibir cómo la Administración es más sensible y se esfuerza comparativamente más en atender las necesidades del Prado quizá porque siente que la opinión pública, nacional o internacional, está mucho más pendiente de la suerte de este. Esto explica las periódicas obras de ampliación y modernización del edificio, así como la creación del Patronato y otras reformas ya comentadas. También desde entonces se empiezan a organizar exposiciones temporales, se modifican las condiciones de exhibición de la colección permanente, se editan catálogos y guías cada vez más completos o se organizan diversas actividades culturales complementarias, como cursos de arte o ciclos de conferencias. Por último, comienzan a multiplicarse los legados de particulares, como los de Fernández Durán, Bosch, Cambó o Villaescusa. Sea como sea, los cambios se van haciendo notar además de por lo antes señalado, por el valor simbólico que 
progresivamente otorgan al Museo del Prado los sucesivos gobiernos y los españoles mismos. Un reflejo vivo de todo esto se pudo apreciar no solo en los momentos dramáticos de la guerra civil, cuando se adoptaron excepcionales medidas de seguridad para proteger el Museo de cualquier eventualidad trágica, medidas que gozaron del fervor y hasta de la espontánea colaboración de la población madrileña, sino también en el hecho de que el amenazado Gobierno de la Segunda República decidiera nombrar director de la institución a Pablo Picasso, entonces ya consagrado como una figura artística internacional, un nombramiento que desde luego no fue pensado para que el genial artista español, afincado en París, ocupara el cargo de manera efectiva, pero que revela la conciencia de la altísima estimación que entonces suscitaba el Museo y el arte español por todo el mundo.

\section{Avatares de la posguerra}

Así y con todo, la propia guerra civil y el terrible empobrecimiento del país en la posguerra, agravado por el cerco internacional al que fue sometida la España dominada por la Dictadura del general Franco, no fueron el mejor caldo de cultivo para mejorar sustancialmente la suerte del Museo del Prado, que sobrevivió un poco a trancas y barrancas, sin que se pudiera resolver ninguno de los problemas de fondo heredados, ni tampoco afrontar los nuevos que se fueron planteando. De todas formas, la última crisis histórica grave padecida por el Museo se comenzó a larvar aproximadamente a partir de la década de 1960, cuando se hizo notar la presión ejercida en este tipo de instituciones por el entonces incipiente turismo cultural de masas, que era fruto, a su vez, del espectacular crecimiento económico de la mayor parte del mundo occidental. A partir de entonces, los grandes museos de todo el mundo vieron desbordadas todas sus expectativas tradicionales, no solo porque se multiplicó por mil el número de sus visitantes, sino porque variaron cualitativamente sus exigencias. A causa de ello, los museos debieron acometer nuevas reformas estructurales en el edificio y en la forma de funcionar, y no ya, o no solo como era habitual, por la búsqueda de espacios más holgados para dar cabida a nuevas obras o para una exhibición más apropiada de las antiguas, sino, sobre todo, para atender al público de una forma más adecuada, lo que suponía disponer áreas de recepción, de formación, de recreación, de descanso, etc., junto a otros muchos y muy diversos servicios, lo que revolucionó, en el fondo y en la forma, la vida de los museos.

Por lo demás, la afluencia masiva fue causa de que se generase una honda preocupación por las condiciones ambientales de conservación de las obras, ya de suyo amenazadas por el fenómeno de la contaminación atmosférica de las ciudades. Se hizo entonces imprescindible dotar a los museos de una climatización artificial, multiplicar los sistemas de vigilancia y reforzar los talleres de restauración. Por último se varió por completo el criterio de museo, que pasó de ser un simple mausoleo yerto a un organismo vivo, que debería en principio ser capaz de organizar cuantas actividades culturales se requiriesen sin por eso desatender las labores de investigación y estudio que le eran consustanciales. Podríamos seguir así haciendo recuento de todo ese interminable catálogo de novedades que la nueva situación social produjo en relación con los museos, pero creo que con lo antedicho basta para hacerse una idea del formidable problema que casi súbitamente se planteó. 


\section{La revolución en marcha}

Pero, si antes de tratar acerca de cómo afrontó este problema el Museo del Prado, he querido dejar constancia de su naturaleza universal a partir de aproximadamente la década 1960, que es cuando se manifestó en toda su virulencia, ha sido porque ahora seguimos pagando no haber sabido reaccionar a tiempo. No es ciertamente que no se hiciera nada -el Prado acometió la climatización artificial a fines de la década de 1970, y, durante los últimos veinticinco años, ha visto multiplicado el número de algunos de los segmentos de su personal, como el de celadores, además, como ya se ha recalcado, de haber ampliado su espacio mediante la creación de nuevas salas de exhibición, la incorporación del adyacente Casón del Buen Retiro o, en fin, el incremento comparativamente espectacular de su dotación presupuestaria, su conversión en organismo autónomo y, finalmente, en organismo público de carácter especial-; no obstante, todas estas medidas tomadas con las precipitadas urgencias de lo acometido a destiempo no habían sobrepasado hasta ahora la categoría del simple parcheo, que, apenas lograba cubrir una clara deficiencia, ponía en evidencia otras tantas, cuando no las generaba, como, por ejemplo, ocurrió con el tema de la creación de nuevos espacios para oficinas, talleres, tiendas o cafetería que se hacía a costa de restar espacio de exhibición. En este sentido, se puede afirmar, sin exagerar, que es en este momento cuando se ha iniciado la revolución, pendiente desde hace muchos años, de la modernización del Museo del Prado en el sentido que se plantea en todo el mundo a partir de los años sesenta del siglo xx, la revolución que convierta lo que es una de las mejores colecciones artísticas del mundo en un museo pleno, porque un museo es hoy más que una simple colección.

Cuando se piensa que, con motivo de la celebración de su segundo centenario, que tuvo lugar en 1993, el Musée du Louvre ultimó sus obras de remodelación por un importe global de más de mil millones de euros, lo que, entre otras cosas, le permite recibir, en las mejores condiciones, a un número de visitantes que rondan los diez millones al año, y lo comparamos con la situación de nuestro primer Museo, que viene reclamando desde hace años lo más elemental y urgente - más espacio físico, más medios humanos y técnicos, más presupuesto ordinario, un sistema de administración más ágil y eficaz, etc.-, se comprende que el brutal desajuste entre ambos museos no responde únicamente a la diferente renta per cápita de ambos países, sino a una radical diferencia de actitud respecto a la institución por parte de las respectivas sociedades y sus representantes políticos.

El Prado, por otra parte, y es primordial señalarlo aquí, ha sufrido despojamientos que es impensable que los hubiera sufrido el Louvre, no siendo los menos perjudiciales los más cercanos en el tiempo. Y en este sentido es importante recordar que en 1992 al Museo del Prado le fue sustraído el legado Picasso y una buena porción de las mejores obras de la vanguardia histórica que le habían sido específicamente donadas por sus autores o sus propietarios.

Este último tema tiene mayor importancia que lo que por sí mismo revela cualquier despojamiento arbitrario infligido a una colección de la categoría de la del Museo del Prado, ya que nos plantea cómo debemos concebir la naturaleza «histórica» de cualquier museo, a partir de cuya confusión se pueden derivar no pocos males para la institución afectada, que así puede ver arrebatado el propio sentido que originalmente justificó su existencia. Quiero decir que el Museo del Prado contiene no solo obras maestras de pinturas de los últimos cinco o seis siglos, sino también un 
formidable conjunto de esculturas clásicas y modernas, algunas de las cuales se remontan en antigüedad a seis siglos antes de Cristo, como la cabeza de un funcionario egipcio, por no hablar de otras, grecorromanas, que fueron expresamente adquiridas en Italia para Felipe IV por el mismísimo Velázquez, pero que, además, posee formidables ejemplos de artes suntuarias e industriales de todas las épocas, culturas y civilizaciones. Por otra parte, tampoco conviene olvidar que el Museo del Prado acogió obras de arte contemporáneo de la forma más natural hasta fechas relativamente recientes, lo que explica la presencia en su colección de obras de los siglos XIX y XX, cuya pobreza artística comparativa fue, en todo caso, el resultado de la decadencia, la conflictividad y el aislamiento de nuestro país durante la época contemporánea. Es verdad que el surgimiento de los museos llamados de arte contemporáneo obligó coyunturalmente a definir los límites de los museos históricos, tratando de preservar a estos del embate de las modas al dictado de la cada vez más enervante actualidad, a la vez que se trataba así de defender mejor las propuestas de vanguardia inicialmente rechazadas por la mayor parte de la sociedad, pero este nuevo acoplamiento de las colecciones públicas no puede llevarse a cabo impidiendo el desarrollo natural de museos como el Prado, que, por naturaleza, ha de estar preparado para recoger, con la debida perspectiva, lo que cada sucesivo presente aporta artísticamente, en cuanto, como es ley natural, ese presente se transforma de súbito en pasado. Debe hacernos meditar que el hasta hace poco considerado máximo heraldo de la vanguardia artística del siglo xx, Pablo Picasso, se ha convertido ya en un artista nacido ¡hace dos siglos!, pues, como es sabido, el genial malagueño vino al mundo en 1881, durante el siglo XIX, lo que históricamente le ubica, una vez traspasado el umbral del siglo XXI, en el mismo lugar en que cronológicamente hasta hace poco situábamos a Goya.

Es mi deseo que, con este rápido recorrido a través de la historia del Museo del Prado, haya contribuido en algo a enriquecer la información y el conocimiento del lector acerca de esta venerable institución, la que sin duda más acredita a España en el extranjero, pero, sobre todo, espero que con estas líneas le haya ayudado efectivamente a amarla con inteligencia, pues, sin pasión, poco se tiene que hacer en cuestiones artísticas, sea cual sea el objeto y el lugar donde en concreto esté atesorado, pero, sin pasión en el Prado, un museo que fue fruto de una pasión continuada, nada es franqueado.

Desde que en el año 2002 Miguel Zugaza asumiera la dirección del Museo se han emprendido diversos cambios asentados en tres pilares básicos: la ampliación, la modernización y la actividad y el servicio. En virtud de la ley reguladora del Museo Nacional del Prado aprobada en noviembre de 2003, la institución pasó de ser un organismo autónomo a constituirse en un ente público; este trascendental cambio en su naturaleza y sistema de gestión ha permitido a sus máximos responsables iniciar una nueva etapa cuya visión global de las diversas áreas y de sus necesidades ha facilitado que se afronte el desafío, largamente aplazado, de su puesta al día museográficamente hablando, que tiene como hito principal la inauguración de la ampliación de la sede del Museo en 2007 y que continúa con la reordenación de sus colecciones con el objetivo de presentar de manera más amplia y en las condiciones museográficas más idóneas los fondos del Museo. Lo que no quiere decir, ni muchísimo menos, que haya que ponerlo «patas arriba». En este sentido, quiero recordar lo que al respecto escribió el sabio Eugenio d'Ors en uno de sus ensayos más populares y reeditados, precisamente en el celebérrimo Tres horas en el Museo del Prado, donde en el prólogo de la undécima edición del libro, y haciendo referencia a las mejoras habidas en 
el Prado, durante los años que separaban la primera y la undécima edición, afirmaba, con su característico gusto por la paradoja, que la institución, en efecto, «había mejorado mucho, justamente como consecuencia de haberse transformado poco». Obviamente, d'Ors no se declaraba con ello refractario a los cambios que los museos, por las causas históricas que hemos comentado más arriba de su progresiva masificación, se han visto obligados a acometer, sino a la necesidad de plantear con mucho tiento cualquier intervención en instituciones no solo centenarias, sino con la solera -la personalidad- del Prado, aviso este particularmente oportuno para los que actúan alocadamente, creyendo que el mucho mudar, sin más norte que el de las modas, es sinónimo del buen hacer. Lo que verdaderamente necesita el Prado es una radical transformación de las condiciones materiales, llevada a cabo, además, con criterio, lo opuesto a la espontánea afición española por el arbitrismo de café y periódico.

Por todo ello, este brevísimo ensayo histórico sobre el Museo del Prado concluye con una cita de otro de sus más cualificados amantes, Juan Antonio Gaya Nuño, el cual, en su magnífica Historia del Museo del Prado, escrita en 1969 con motivo de la celebración del ciento cincuenta aniversario de la institución, decía lo siguiente:

«En la historia comprimidísima que aquí concluye se han visto elogios y reproches, en cuya distribución se trató de proceder con la mayor justicia. Como quiera que sea, alabando cuanto quepa alabar, censurando todo cuanto merezca censura, colaborando - se desee o no- en una empresa que es de todos, de algo no hay que dudar, y ese algo lo trae la certeza de que el Museo del Prado ha sido, es y será la realidad cultural más gloriosa de España y una de las máximas de todo el planeta [...]. El Museo del Prado es un precioso don de cuya custodia inmediata se confía, solo a título muy relativo y precario, a un hombre, a dos, a tres, hasta el más reciente de sus celadores; mas otra guarda, otra custodia y otra estima no menos activas han de preservar en el ánimo y en el corazón de los hombres que sigan creyendo en los valores de lo maravilloso. El Museo del Prado es nuestro museo, nuestra casa, nuestro amor, nuestro consuelo de muchísimas circunstancias negativas y contrarias. Por lo menos en cuanto a la magnitud de ese amor, todo español debería sentirse un poco director $-\mathrm{y}$, naturalmente, para serlo, sentirse también primer servidor- de nuestro gloriosísimo Museo del Prado». 